\title{
Development of Manufacturing Technology of Nozzles from Composite Materials during Radiation Cooling
}

\author{
Minggong Sha ${ }^{\text {a }}$, Lev Rabinskiy ${ }^{\text {b, }}$, Yuri A. Utkin ${ }^{b}$ \\ ${ }^{a}$ School of Civil Aviation, Northwestern Polytechnical University (NPU), Xi'an Shaanxi, 710072, P.R.China \\ ${ }^{b}$ Moscow Aviation Institute (National Research University), Moscow, 125993, Russian Federation \\ Corresponding author: *danonik92@mail.ru
}

\begin{abstract}
Carbon-carbon composite materials (CCCM) are a new class of structural materials designed to create light, durable, and space-based rigid structures for aerospace, hypersonic, gas turbine engines, parts of nozzle blocks, rocket combustion chambers, and transition trusses. They have the unique ability to maintain high strength and stiffness with $2500^{\circ} \mathrm{C}$. For the manufacture of thermally stressed parts of nozzles, carbon fiber fabrics are used. Antioxidant coatings based on tantalum and silicon are applied to nozzles with adhesive (made based on tantalum carbide, which provides high mechanical strength of adhesion of erosion-resistant antioxidant coating with CCCM), antioxidant and erosion-resistant layers. To deposit a layer of tantalum carbide on CCCM, we used the technology of vacuum ion-plasma deposition of tantalum film followed by carbonization with carbon. As a result, an adhesive coating of tantalum carbide is formed on the surface of the packing. Obtaining an erosion-resistant antioxidant coating on the adhesion layer of tantalum carbide is obtained by applying a slip of silicon carbide powders and soot. The study of the performance of antioxidant and erosionresistant protective coating in high-temperature airflow was carried out on plasmatron (it is a plasma generator in which an electric current is used to form a plasma; for cooling it, channels washed by water are used). This article shows that the studied packings have a unique ability to maintain high strength and rigidity with $2500^{\circ} \mathrm{C}$. There is the expediency of manufacturing such nozzles. The physical and mechanical characteristics of the material were determined.
\end{abstract}

Keywords - Carbon-carbon composite material (CCCM); model nozzle; erosion-resistant composite material; physical and mechanical characteristics; design documentation; radiation cooling nozzle (RCN).

\section{INTRODUCTION}

One of the important problems of creating designs for various types of engines is the development of new materials used to manufacture the most loaded parts operating under the influence of highly enthalpy products of combustion of liquid components. The development of heat resistant material for the nozzle extension, antioxidant coating, and change in the geometry of the inner surface of the nozzle extension will increase the efficiency of the engines of the upper stages. Heat-stressed structures must be protected from hightemperature gas corrosion and erosion. Traditionally used coatings based on silicon and corundum can significantly increase the operating temperature of structures. Concerning the heat resistance of materials, structural graphite CCCM with the highest specific strength and rigidity up to $2800^{\circ} \mathrm{C}$, high heat resistance, impact strength, corrosion resistance, resistance to radiation exposure, and low-temperature linear expansion coefficients are very interesting for designers. Reducing the weight of the structures causes the use of CCCM in the hot elements of the design products of rocket and space technology.

CCCM is a new class of structural materials designed to create light, durable, space-based rigid structures for aerospace, hypersonic, gas turbine engines, parts of nozzle blocks, rocket combustion chambers, and transition trusses. They have the unique ability to maintain high strength and rigidity at temperatures up to $2500^{\circ} \mathrm{C}$. For the manufacture of thermally stressed parts of the nozzles, carbon fiber fabrics are used.

The nozzles are coated with antioxidant coatings based on tantalum and silicon. The investigated nozzles are coated with adhesive, antioxidant, and erosion-resistant layers. The adhesion layer is made based on tantalum carbide, which provides high mechanical strength of the adhesion of the erosion-resistant antioxidant coating to CCCM. To deposit a layer of tantalum carbide on CCCM, the technology of 
vacuum ion-plasma deposition of a tantalum film on CCCM was used, followed by carbonization with carbon. As a result of heat treatment, an adhesive coating of tantalum carbide is formed on the packing surface. Obtaining an erosion-resistant antioxidant coating on the adhesion layer of tantalum carbide is obtained by applying a slip of silicon carbide powders, soot. The technology for creating an antioxidant coating includes forming a silicon carbide coating and forming an outer coating in the form of zirconium diboride.

The study of the performance of an antioxidant, erosionresistant protective coating in a high-temperature airflow was carried out on a plasmatron. A plasmatron is a plasma generator in which an electric current is used to form a plasma. To cool the plasma torch, channels washed with water are used.

This article shows that CCCM packing under study has the unique ability to maintain high strength and rigidity at temperatures up to $2500^{\circ} \mathrm{C}$. The expediency of manufacturing a nozzle attachment from CCCM is shown. The work has been carried out to determine the physical and mechanical characteristics of the material (new augmented abstract).

One of the important problems in creating designs for various types of engines is the development of new materials used to manufacture the most loaded parts operating under conditions of exposure to high-enthaltion products of combustion of liquid components. The development of a heatresistant material of the nozzle attachment, antioxidant coating and change in the geometry of the inner surface of the nozzle attachment will increase the efficiency of the upper stage engines. Heat-stressed structures must be protected against high-temperature gas corrosion and erosion. Traditionally used coatings based on silicon and corundum can significantly increase the operating temperatures of structures. In terms of heat resistance of materials, special attention of designers is attracted by structural graphite, which have the highest specific strength and rigidity up to temperatures of $2800^{\circ} \mathrm{C}$, high heat resistance, impact toughness, corrosion resistance, resistance to radiation exposure, and low-temperature coefficients of linear expansion. The reduction in the weight of structures leads to the use of CCCM in hot elements of design products in rocket and space technology.

To produce perspective engines, it is necessary to create a technology for manufacturing model $\mathrm{RCN}$ of a profiled shape and obtain physical and mechanical characteristics when testing nozzle material.

\section{MATERIAL AND METHOD}

\section{A. Manufacturing technology of model RCN}

During the process of testing the manufacturing technology of a model RCN of a profiled shape. It was found that there are delamination and folds of material passing into the body of the part in the area of the small end on some blanks. In order to reduce the likelihood of occurrence of these defects, the following technical measures have been implemented [1][3]:

- height of the technological allowance of the workpiece from the side of the small end has been increased with the corresponding refinement of technological agile tooling.
- shape and number of petals are adjusted, taking into account changes in the geometry of the workpiece and design of agile tooling.

- securing the position of the petals during molding and heat treatment of the workpiece nozzle.

- pre-testing of the petals placed on the mandrel with an elastic cuff with a degree of stretching in the initial position of at least 2.0 was applied.

To increase the height of the technological allowance from the side of the small end face of the nozzle, additional mandrel elements "Bush" (Figure 1) and "Washer" (Figure 2) were developed, which allow forming a cylindrical section of the technological allowance on the nozzle blank (Figure 3). An interchangeable (technological) ring is designed to ensure the fixation of the petals by the layout on the mandrel [4].

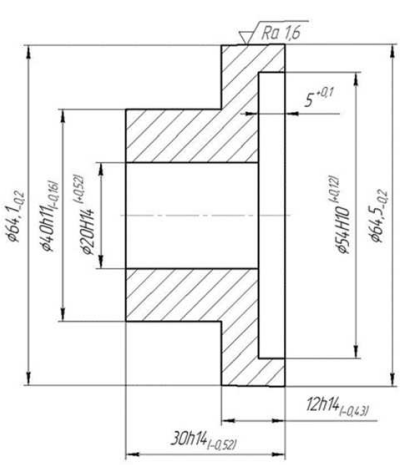

$\sqrt{\operatorname{Ra} 6,3(\sqrt{)}}$

Fig. 1 Bush
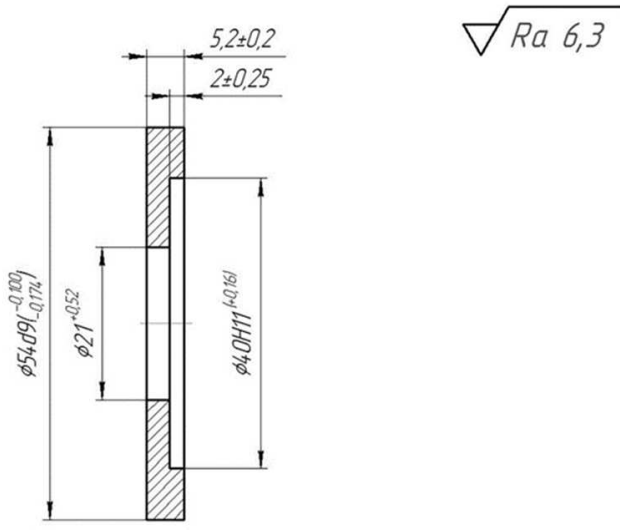

Fig. 2 Washer

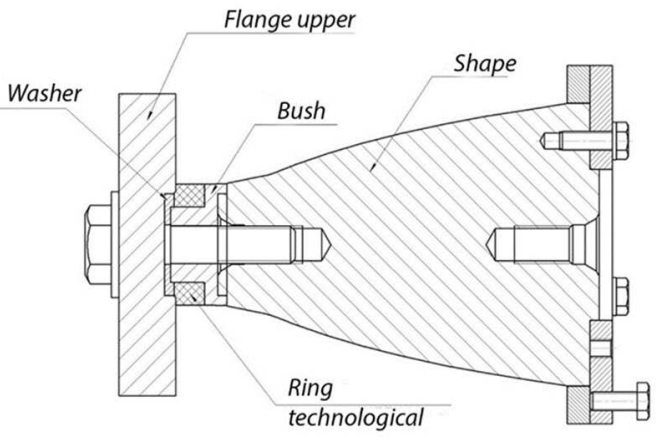

Fig. 3 Mandrel assembly 
A modified mandrel for the manufacture of carbon fiber billet is presented in Figure 4.

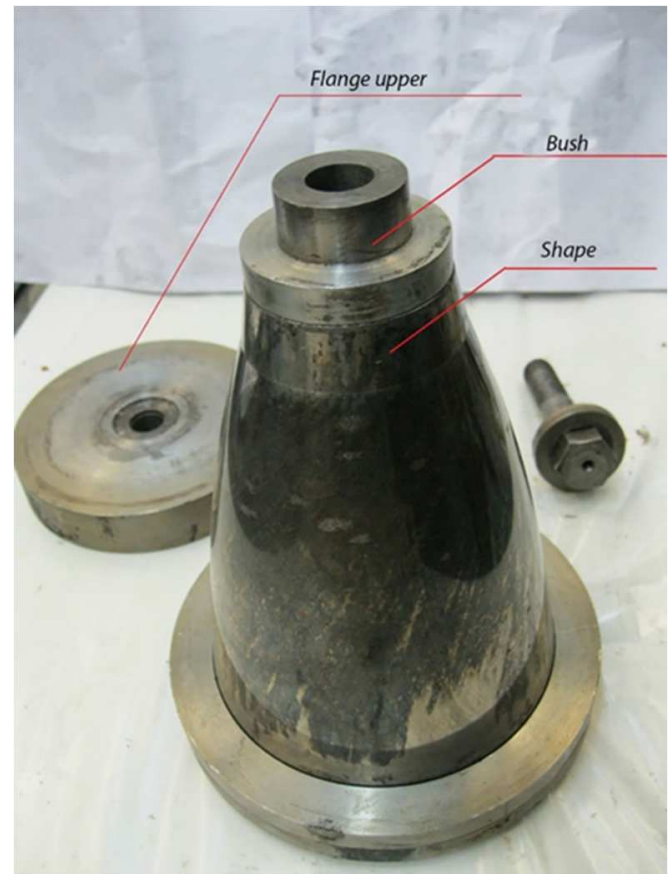

Fig. 4 Modified mandrel for the manufacture of carbon fiber billet

The total number of petals placed on the mandrel is 101 . Petals are pre-glued to 5-point packets with a given step between the petals (Figure 5). The last package consists of 6 petals. The total number of packets is 20 .

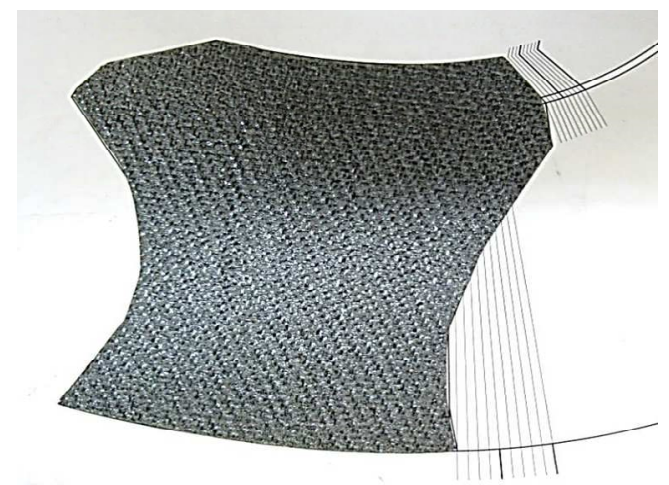

$a$

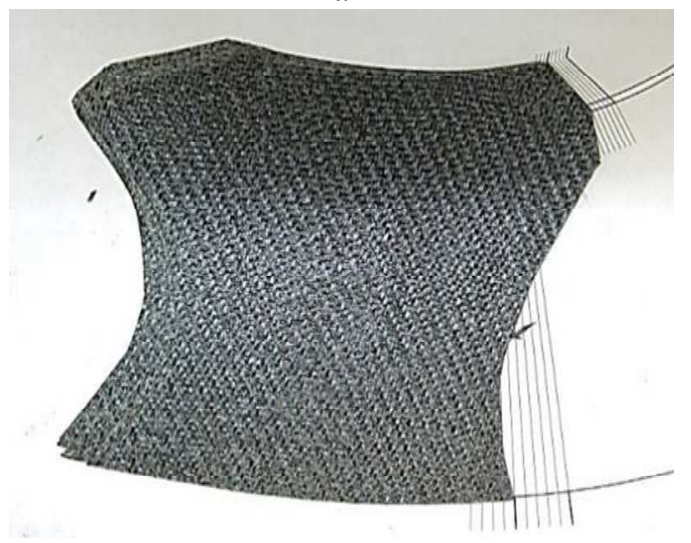

$b$

Fig. 5 Layout of the petals according to the layout in the package $a$ - first petal, $b$ - package of 5 petals
Packing of petal packages is carried out following a given way for marking in the area of the large and small diameter of the mandrel with the rigid fastening of each package to the process ring with clamps (Figure 6).

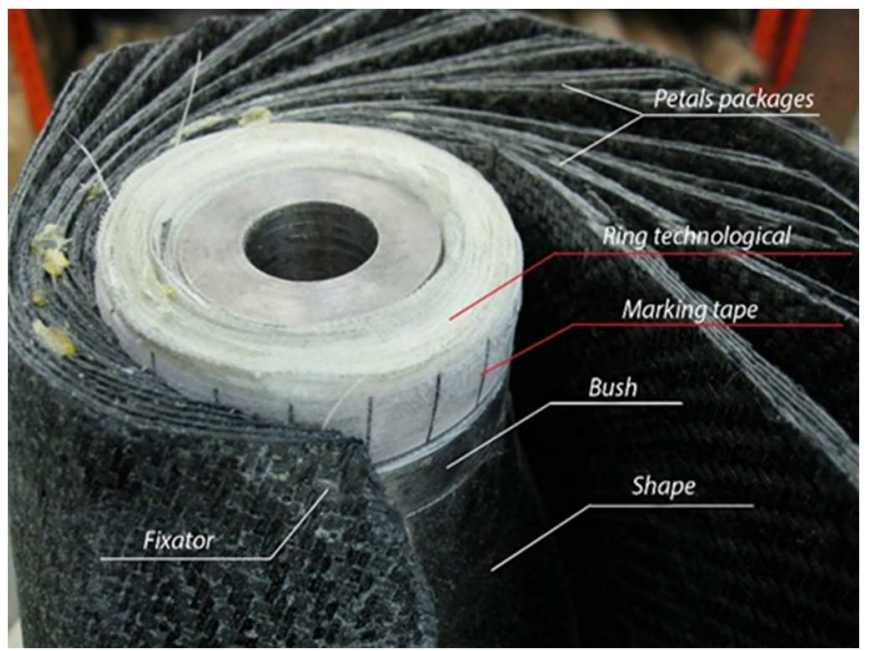

Fig. 6 Laying material packages on a mandrel

Thus, model RCN for testing as a part of model power plants were manufactured taking into account the developed proposals included in the technological process. To conduct experimental studies, 6 profiled shaped model RCN were manufactured. Antioxidant coatings based on tantalum and silicon were applied to them.

\section{B. Manufacturing technology of model RCN}

The studied coating composition consists of adhesive and erosion-resistant antioxidant layers. The adhesive layer is made on the basis of tantalum carbide, which provides high mechanical adhesion to the erosion-resistant antioxidant coating with CCCM of the nozzle and is selected based on the high melting point [5]-[7]. The technology of vacuum ionplasma deposition of a tantalum film on CCCM with subsequent carbonization by carbon from CCCM was used to deposit a high-quality tantalum carbide layer [8], [9]. As a result of heat treatment, an adhesive coating of tantalum carbide is formed on the surface of the nozzle. The process of obtaining an erosion-resistant antioxidant coating on an adhesive layer of tantalum carbide includes the following [10]:

- preparation of a slip from a mixture of powders of $\mathrm{Si}$, C, Hf, B2, and soot;

- applying a slip on the surface of the nozzle with a soft brush in one layer and drying, as well as siliconizing the coating by capillary saturation with liquid silicon in a vacuum oven.

The technology for creating an antioxidant coating includes two stages: forming a silicon carbide coating in a vapor-gas medium of silicon monoxide and forming an external coating in the form of predominantly zirconium diboride. The formation of silicon carbide coatings is carried out in a vacuum induction furnace with a residual argon pressure of $0.5 \mathrm{~atm}$ at a temperature of $1750{ }^{\circ} \mathrm{C}$. Heat treatment of the outer coating is carried out in a nitrogen atmosphere [11]-[13]. 


\section{RESULTS AND DISCUSSION}

\section{A. Manufacturing technology of model RCN}

The study of the performance of the antioxidant protective coating under conditions of high-temperature airflow was carried out on a plasmatron on samples of Ø40xØ30x10 mm. At the same time, the density, open porosity and thermal conductivity of the material of the nozzle with a protective antioxidant coating were determined. In addition, the thermal stability of the coating was evaluated under the influence of a high-temperature gas flow.

Samples were made of composite material, corresponding in composition to the material of the nozzle, in the form of a plate $150 \times 150 \times 15 \mathrm{~mm}$. Upon receipt of the material and the coating on the samples, the heat treatment of the plate was carried out jointly in the manufacture of model RCN. To study the density, porosity and thermal conductivity, the coating on the samples was formed from the end surfaces. For gasdynamic tests, the coating was formed on all surfaces of the samples [14], [15]. The test results of samples with antioxidant coatings are presented in Table 1. Both types of coatings can be perspective for nozzles with a surface temperature during operation up to $1800{ }^{\circ} \mathrm{C}$.
TABLE I

Test Results of SAmples With CoAting on the Plasmatron

\begin{tabular}{lcc}
\hline \multicolumn{1}{c}{ Sample coating } & $\begin{array}{c}\text { Tantalum- } \\
\text { based }\end{array}$ & Silicon-based \\
\hline Exposure time, $\mathrm{s}$ & 1000 & 1000 \\
Crater depth, mm & +0.13 & +0.1 \\
$\begin{array}{l}\text { The initial mass of the } \\
\text { sample, } \mathrm{g}\end{array}$ & 18.88 & 16.49 \\
$\begin{array}{l}\text { Loss of mass of the sample, g } \\
\text { Maximum sample surface }\end{array}$ & 0.00 & +0.05 \\
temperature, ${ }^{\circ} \mathrm{C}$ & 1820 & 1800 \\
\hline
\end{tabular}

\section{B. Study of PMC of CCCM}

To study PMC of a material based on carbon fabric, two $400 \times 330 \times 4 \mathrm{~mm}$ plates were manufactured according to the manufacturing mode of CCCM based on carbon fibres-900 (CF-900). It was impregnated with a phenolic binder. Carbon fibers were manufactured by hot pressing. The number of tissue layers in the plate is 20 ( 5 layers per $1 \mathrm{~mm}$ ). The scheme of cutting plates into samples is shown in Figure 7.

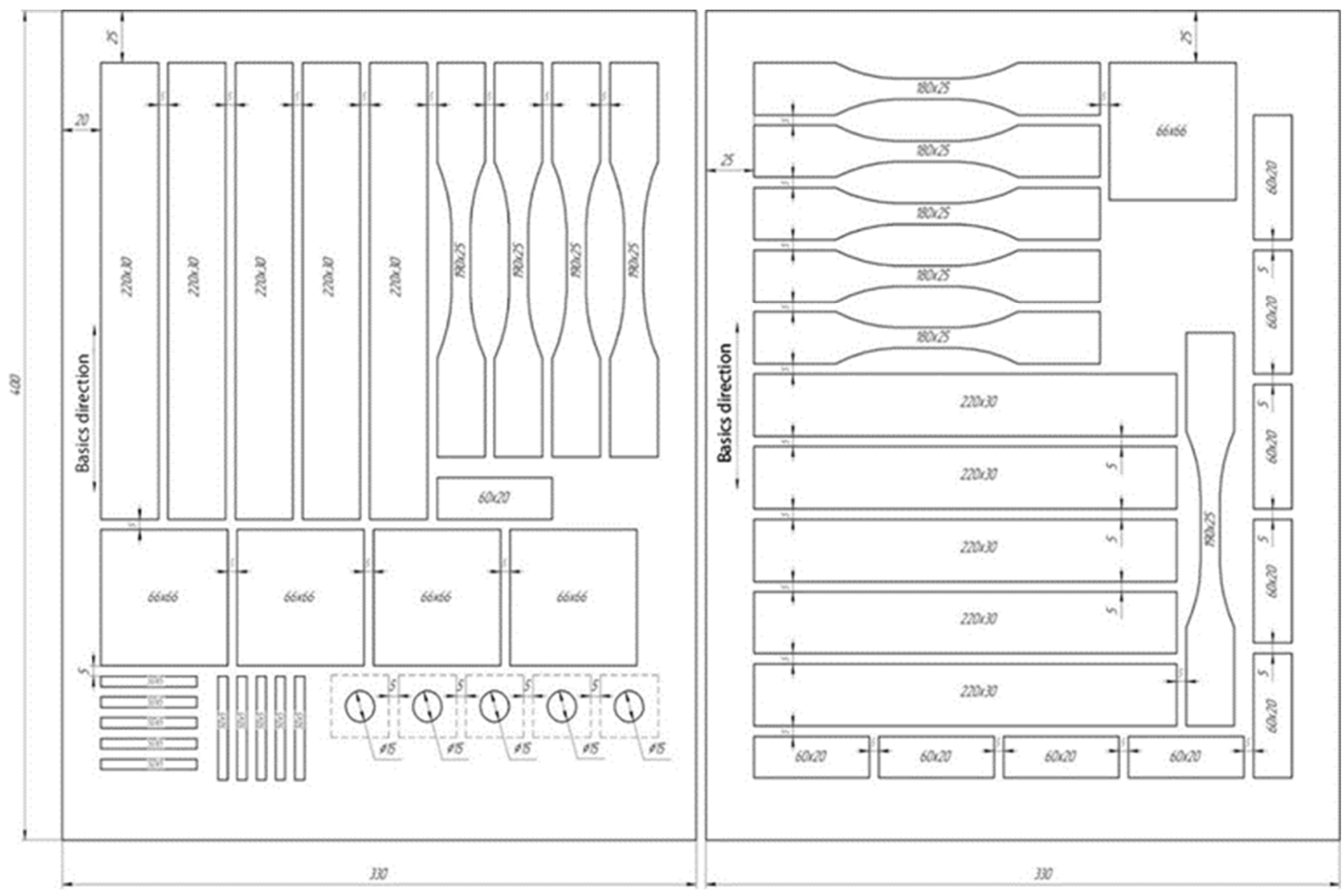

Fig. 7 Scheme of cutting plates into samples

Then carbon fiber underwent carbon redistribution. This changes the mass and thickness of the plates. PMC of CCCM was determined from experimental studies conducted based on the universal testing machine "Instron". The location of the samples on the installation is shown in Figure 8. 


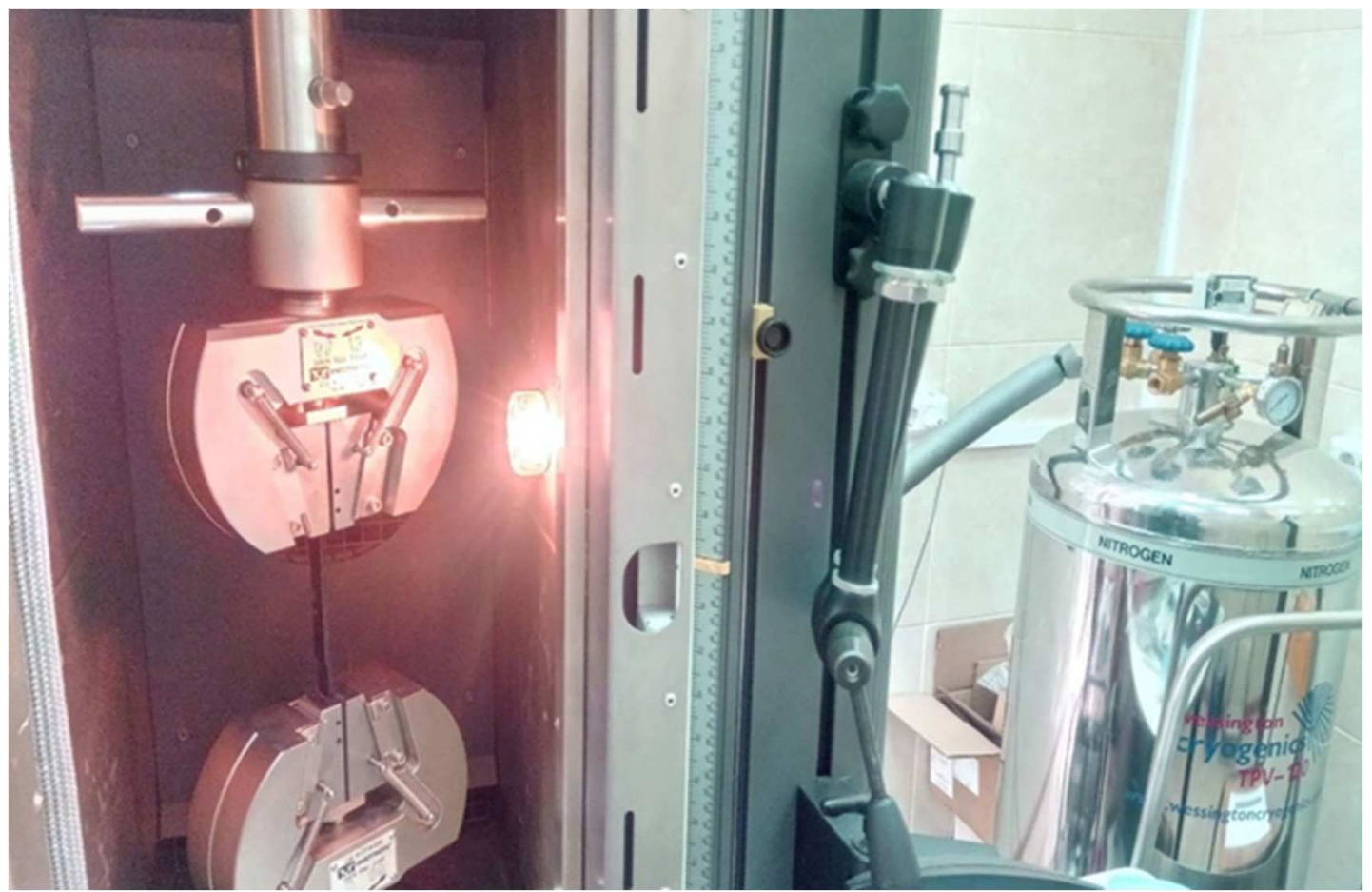

Fig. 8 Sample location before testing

The level of performance achieved in comparison with existing analogs is shown in Table 2.

TABLE II

PMC OF CARBON MATERIALS

\begin{tabular}{|c|c|c|c|}
\hline Material & $\begin{array}{c}\text { Carbon } \\
\text { fabric (90- } \\
\text { degree } \\
\text { filament } \\
\text { angle) }\end{array}$ & Proposed & $\begin{array}{c}\text { Carbon } \\
\text { fabric (45- } \\
\text { degree } \\
\text { filament } \\
\text { angle) }\end{array}$ \\
\hline Matrix & \multicolumn{3}{|c|}{ Phenolic resin coke and pyrocarbon } \\
\hline $\begin{array}{l}\text { Tensile stress tensile along } \\
\text { the base, } \mathrm{MPa}\end{array}$ & 124 & 153 & 260 \\
\hline $\begin{array}{l}\text { Tensile modulus along the } \\
\text { base, MPa }\end{array}$ & 21 & 82.7 & 75 \\
\hline $\begin{array}{l}\text { Breaking stress during } \\
\text { compression along the base, } \\
\text { MPa }\end{array}$ & 145 & 199 & 140 \\
\hline Poisson's ratio along the base & 0.155 & 0.051 & 0.1 \\
\hline Density, $\mathrm{kg} / \mathrm{m}^{3}$ & 1.32 & 1.53 & 1.45 \\
\hline $\begin{array}{l}\text { Thermal conductivity } \\
\text { coefficient at } 20 \pm 5^{\circ} \mathrm{C} \text { in the } \\
\text { direction perpendicular to } \\
\text { the layers, } \mathrm{W} /(\mathrm{m} \cdot \mathrm{K})\end{array}$ & 2.5 & 2.0 & $1.4 \div 2.8$ \\
\hline $\begin{array}{l}\text { Coefficient of linear thermal } \\
\text { expansion, } 10^{-6} \mathrm{~K}^{-1} \\
\text { at a temperature, } \mathrm{T}^{\circ} \mathrm{C}\end{array}$ & \multicolumn{3}{|c|}{$\begin{array}{l}\text { the direction of coefficient of linear } \\
\text { thermal expansion measurements }\end{array}$} \\
\hline 100 & 1.37 & 1.35 & 1.3 \\
\hline 300 & 1.77 & 1.80 & 1.84 \\
\hline 500 & 2.09 & 2.13 & 2.15 \\
\hline 900 & 2.53 & 2.59 & 2.63 \\
\hline
\end{tabular}

\section{CONCLUSION}

The studies showed that the model RCN with a profiled shape with two types of antioxidant coatings made according to the above-mentioned technology could be considered promising engines with a nozzle at a surface temperature during operation of $1200{ }^{\circ} \mathrm{C}$. Analysis of the physicomechanical characteristics obtained during experimental studies carried out on a tensile testing machine showed a significant improvement in stress indicators for a tantalum sample of $124 \mathrm{MPa}$ and a sample based on silicon it is twice as high, in the modulus of elasticity of $21 \mathrm{MPa}$ for tantalum, a silicon base is three times higher. Times higher, in terms of the coefficient of thermal conductivity, the samples based on tantalum and silicon have the same values.

The presence on the surface of the sample of heat-resistant antioxidants made of a mixture of $\mathrm{Si}, \mathrm{C}, \mathrm{Hf}, \mathrm{B}_{2}$, and soot did not lead to a change in the material's thermal conductivity. Tests on a plasmatron showed that composite samples based on tantalum are more resistant to mass carryover. There is practically no carryover from the tantalum sample. The weight loss from the silicon-based sample is $0.05 \mathrm{~g}$, although the specimens based on tantalum withstand higher temperatures of $1820^{\circ} \mathrm{C}$ based on silicon $1800^{\circ} \mathrm{C}$.

\section{ACKNOWLEDGMENTS}

The work was carried out at Moscow Aviation Institute with the financial support of Russian Foundation for Basic Research, project № 18-29-18083/18.

\section{REFERENCES}

[1] B. A. Antufev, O. V. Egorova, and L. N. Rabinskiy, "Dynamics of a cylindrical shell with a collapsing elastic base under the action of a pressure wave," INCAS Bull., vol. 11, pp. 17-24, 2019.

[2] L. N. Rabinskiy, "Non-stationary problem of the plane oblique pressure wave diffraction on thin shell in the shape of parabolic cylinder," Per. Tche Quim., vol. 16, no. 32, pp. 328-337, 2019.

[3] B. A. Antufev, O. V. Egorova, A. L. Medvedskii, and L. N. Rabinskiy, "Dynamics of shell with destructive heat protective coating under running load," INCAS Bull., vol. 11, pp. 7-16, 2019.

[4] B. A. Antufev, O. V. Egorova, and L.N. Rabinskiy, "Quasi-static stability of a ribbed shell interacting with moving load," INCAS Bull., vol. 11 , pp. 33-39, 2019.

[5] A. G. Getmanov, and L. N. Rabinskiy, "Assessment of durability of coatings in difficult stress conditions," Per. Tche Quim., vol. 16, no. 33, pp. 490-497, 2019.

[6] V. G. Dmitriev, O. V. Egorova, and L. N. Rabinsky, "Solution of nonlinear initial boundary-value problems of the mechanics of multiply connected composite material shells on the basis of 
conservative difference schemes," Comp.: Mech., Comp., Appl.: An Int. Journ.," vol. 6, no. 4, pp. 265-277, 2015.

[7] V. G. Dmitriev, O. V. Egorova, S. I. Zhavoronok, and L. N. Rabinsky, "Investigation of buckling behavior for thin-walled bearing aircraft structural elements with cutouts by means of numerical simulation," Russ. Aer., vol. 61, no. 2, pp. 165-174, 2018.

[8] A. N. Danilin, L. N, Rabinskiy, and S. I. Zhavoronok, "Deformation of the helical type wire structures," Per. Tche Quim., vol. 16, no. 33, pp. 583-601, 2019.

[9] L. N. Rabinskiy, and O. V. Tushavina, "Experimental investigation and mathematical modelling of heat protection subjected to hightemperature loading," Per. Tche Quim., vol. 15, no. S1, pp. 321-329, 2018

[10] L. N. Rabinskiy, and O. V. Tushavina, "Investigation of an elastic curvilinear cylindrical shell in the shape of a parabolic cylinder, taking into account thermal effects during laser sintering," As. Lif. Scienc., vol. 2, pp. 977-991, 2019.
[11] V. F. Formalev, S. A. Kolesnik, and E. L. Kuznetsova, "The effect of longitudinal nonisothermality on conjugate heat transfer between wall gasdynamic flows and blunt anisotropic bodies," High Temp., vol. 47, no. 2, pp. 228-234, 2009.

[12] D. A. Kozorez, and D. M. Kruzhkov, "Autonomous navigation of the space debris collector," INCAS Bull., vol. 11, pp. 89-104, 2019.

[13] V. N. Evdokimenkov, D. A. Kozorez, and M. N. Krasilshchikov, "Development of pre-flight planning algorithms for the functionalprogram prototype of a distributed intellectual control system of unmanned flying vehicle groups," INCAS Bull., vol. 11, pp. 75-88, 2019.

[14] V. N. Evdokimenkov, N. V. Kim, D. A. Kozorez, and M. I. Mokrova, "Control of unmanned aerial vehicles during fire situation monitoring," INCAS Bull., vol. 11, pp. 67-73, 2019.

[15] A. V. Ryapukhin, V. V. Kabakov, and R. N. Zaripov, "Risk management of multimodular multi-agent system for creating scienceintensive high-tech products," Esp., vol. 40, no. 34, p.19, 2019. 